\title{
Uma proposta de aperfeiçoamento do PNLD como política pública: o livro didático como capital cultural do aluno/família
}

\author{
Cristiano Amaral Garboggini Di Giorgi* \\ Silvio Cesar Nunes Militão** \\ Andréia Nunes Militão*** \\ Fabio Perboni ${ }^{\star \star \star \star}$ \\ Regina Célia Ramos***** \\ Vanda Moreira Machado Lima****** \\ Yoshie Ussami Ferrari Leite ${ }^{\star \star \star \star \star \star *}$
}

\section{Resumo}

O artigo problematiza uma importante dimensão da educação na atualidade e aponta sugestões para o aperfeiçoamento do Programa Nacional do Livro Didático (PNLD), considerando sua importância para a melhoria da qualidade da educação brasileira. Os procedimentos metodológicos adotados para a elaboração deste trabalho constituem-se de pesquisa bibliográfica e documental, aplicação de questionário junto a 36 professores dos anos iniciais do ensino fundamental de uma rede municipal de educação no interior do Estado de São Paulo. Defendemos que o PNLD pode constituir-se num elemento para a ampliação do capital cultural dos alunos, em especial, das camadas mais desfavorecidas da sociedade que, de modo geral, não têm acesso a livros, além de relevante recurso didático no trabalho pedagógico dos professores. Propomos, mediante análise crítica, que o PNLD

\footnotetext{
* Professor Titular, FCT/UNESP; Professor do Programa de Pós-graduação e do Departamento de Educação da FCT/UNESP. E-mail: digiorgi@ig.com.br

** Doutor em Educação, FFC/UNESP; Professor do Departamento de Educação da FCT/UNESP. E-mail: nmsilvio@ig.com.br

***Mestre em História, FHDSS/UNESP; Doutoranda em Educação pelo Programa de Pós-graduação em Educação da FCT/UNESP. Bolsista FAPESP. E-mail: andreianmilitao@terra.com.br

****Mestre em História, FHDSS/UNESP; Doutorando em Educação pelo Programa de Pós-graduação em Educação da FCT/UNESP; Professor da Faculdade de Educação na Universidade Federal da Grande Dourados. FAED/UFGD. E-mail: fabioperboni@terra.com.br

*****Mestre em Educação, FCT/UNESP; Professora do Departamento de Matemática. E-mail: receramos@ uol.com.br

******Doutora em Educação, FE/USP; Professora do Departamento de Educação da FCT/UNESP. E-mail: moreiravanda@ig.com.br

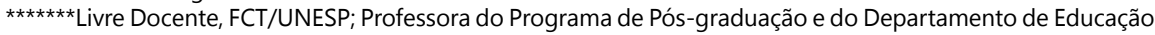
da FCT/UNESP. E-mail: yoshie@fct.unesp.br
} 
distribua livros didáticos consumíveis a todos os alunos da educação básica.

Palavras-chave: Livro Didático. PNLD. Políticas Públicas. Capital Cultural.

\section{Introdução}

No tempo presente, a discussão sobre o uso e/ou não uso do livro didático por escolas, professores e alunos ainda se constitui enquanto tema polêmico. De modo geral, os estudos sobre essa temática privilegiaram mais a discussão de temas como: a autonomia do professor, os conteúdos dos livros, a presença de viéses ideológicos nos mesmos, os erros conceituais presentes nas obras, a memória sobre o uso do livro escolar e, ainda, a especificidade desses materiais para cada disciplina escolar.

Gestou-se uma visão negativa em relação ao livro didático, associada, principalmente, ao caráter mercadológico de produção e comercialização destes. Soma-se a essa questão a discussão acerca da baixa qualidade dos mesmos, situação que passou a ser combatida a partir da criação do Programa Nacional do Livro Didático (PNLD). Entendemos que, embora este programa não tenha solucionado todas as críticas e possíveis problemas, teve o mérito de submeter toda a produção a um processo avaliativo, que contribuiu sobremaneira para a melhoria da qualidade dos livros didáticos que chegam as escolas públicas brasileiras.

As resistências e críticas ao livro didático datam da década de 1970, intensificando-se nos dez anos seguintes, momento em que se disseminou a ideia de que essas obras eram "uma tecnologia pouco adequada a processos efetivos de aprendizado". Também foi alvo de críticas por ser visto "como resultado de interesses econômicos envolvidos em sua produção e comercialização". Por último, seu uso foi associado à ideia de controle sobre o trabalho docente e, consequentemente, sobre o currículo (BATISTA, 2003, p. 45, apud TAGLIANI, 2011, p.137).

Sem desconsiderar a importância das diversas abordagens dos estudos que tiveram/ têm como objeto de investigação o uso do livro didático e, especificamente, sobre o PNLD, propomos, aqui, analisar aspectos que permeiam a política nacional de distribuição do livro didático, explicitando as dificuldades encontradas tanto na forma execução como na aceitação social do PNLD. 
Defendemos que os livros didáticos devem ser consumíveis, apoiado em três argumentos: primeiro, que estes podem contribuir na constituição de um capital cultural, e, nesse sentido, uma mudança no PNLD traria a possibilidade de o aluno permanecer com os livros em casa, tanto para uso próprio como para uso dos familiares como um material de consulta e de estudo.

Um segundo aspecto é que pesquisa recente (FUNDAÇÃO LEMANN, 2009) confirma a aceitação, pelos pais e professores, dos chamados sistemas apostilados que utilizam materiais assemelhados ao de modelo dos livros didáticos. Uma hipótese para explicar esse fenômeno é a de que esses materiais, por serem de caráter consumível, permanecem com os alunos e não são devolvidos ao término do ano letivo. Isso permite ao professor uma economia de tempo, pois, não havendo de passar conteúdos na lousa, ampliam-se as possibilidades didáticas do uso do próprio livro, além de permitir um tempo maior para acompanhar os alunos em suas dificuldades, com vantagens didáticas em relação ao modelo atual.

Por fim, entendemos que o custo dessa mudança não representa um impacto significativo na dotação orçamentária do Ministério da Educação (MEC). Com base nos custos atuais do PNLD, apresentamos um cálculo referente a um período de três anos.

É na dimensão microssocial que se situa a presente argumentação, defendendo que o aluno possa dispor de material próprio para consulta, escrita e análise; ou seja, que possa ficar e utilizar pedagogicamente o livro didático em sala de aula durante todo o ano letivo, escrever no próprio livro, fazendo nele suas atividades e, posteriormente, levar o livro para sua casa.

Para construção deste trabalho, recorremos à pesquisa bibliográfica e documental, dialogando com a produção acadêmica da área e pesquisando em arquivos digitais do MEC, documentos que normatizam o programa PNLD. Realizamos, também, a aplicação de um questionário com professores dos anos iniciais de uma rede municipal de educação sobre planejamento e a escolha do PNLD.

\section{Programa Nacional do Livro Didático}

O PNLD assumiu seu formato atual somente em meados da década de noventa, entretanto, sua origem remonta a 1929, com a criação do Instituto Nacional do 
Livro (INL), órgão específico para legislar sobre políticas do livro didático. Contudo, seu funcionamento se inicia somente em 1934, durante o governo Vargas, assumindo um caráter geral de incentivo à leitura.

Para Silva (2012, p. 805), a permanência do livro didático nas escolas está relacionada à "[...] capacidade que editores e autores demonstraram ao longo da história da educação brasileira de adaptar o livro didático às mudanças de paradigmas, alterações dos programas oficiais de ensino, renovações de currículos e inovações tecnológicas [...]”.

Esse programa inicial foi alterado inúmeras vezes, adquirindo diferentes nomenclaturas e formatos de funcionamento. Neste sentido, a Comissão Nacional do Livro Didático (CNLD), criada em 1938, estabelece a primeira política nacional de legislação para tratar da produção, do controle e da circulação dessas obras no país.

Um aspecto importante desse momento histórico, identificado por Soares (1996 apud SILVA 2012), é a longa duração do uso de cada edição. Assim, era comum que alguns livros didáticos fossem empregados continuamente por volta de 50 anos.

Posteriormente, em 1966, foi realizado um acordo entre o Ministério da Educação (MEC) e a Agência Norte-Americana para o Desenvolvimento Internacional (USAID), permitindo a criação da Comissão do Livro Técnico e Livro Didático (COLTED). Esse processo não esteve isento de críticas por parte de educadores brasileiros, uma vez que ao MEC e ao Sindicato Nacional de Editores de Livros (SNEL) caberiam apenas as responsabilidades de execução e aos órgãos técnicos da USAID, todo o controle.

Um elemento inovador da década de 1960 é que "os livros didáticos passaram a ser escritos, via de regra, por professores de formação específica nas áreas sobre as quais escreviam e, de um modo geral, em exercício nas séries para as quais seus livros eram destinados" (SILVA, 2012, p. 809). Esse aspecto é positivo, uma vez que era comum que livros didáticos fossem escritos por pessoas sem formação na área específica e/ou que nunca tivessem atuado no nível de ensino para o qual produziam os referidos materiais. 
A partir de 1971, o INL passa a desenvolver o Programa do Livro Didático para o Ensino Fundamental (PLIDEF), assumindo as atribuições administrativas e de gerenciamento dos recursos financeiros, até então, a cargo da COLTED.

Com a extensão do INL, em 1976, foi criada a Fundação Nacional do Material Escolar (FENAME), que se tornou responsável pela execução do PLIDEF. A partir desse momento, o governo iniciou a compra dos livros com recursos do Fundo Nacional de Desenvolvimento da Educação (FNDE) e com as contribuições dos Estados.

Höfling (2000, p. 164) observa que:

Em abril de 1983, foi criada a Fundação de Assistência ao Estudante (FAE), absorvendo os programas que eram da alçada da Fename e do Inae, órgãos vinculados ao MEC. No mesmo ano, o Programa do Livro Didático (Plid) foi incorporado à FAE. Em 1984, deu-se fim ao sistema de coedição, passando o MEC a ser comprador dos livros produzidos pelas editoras participantes do Plid.

O Decreto $n^{\circ}$ 91.542, de 19/8/85 apresenta algumas mudanças no PNLD:

- Indicação do livro didático pelos professores;

- Reutilização do livro, implicando a abolição do livro descartável e o aperfeiçoamento das especificações técnicas para sua produção, visando maior durabilidade e possibilitando a implantação de bancos de livros didáticos;

- Extensão da oferta aos alunos de $1^{\mathrm{a}}$ e $2^{\mathrm{a}}$ série das escolas públicas e comunitárias;

- Fim da participação financeira dos estados, passando o controle do processo decisório para a FAE e garantindo o critério de escolha do livro pelos professores (BRASIL, 2012).

O PNLD substituiu o PLIDEF, em 1985 (Decreto $\mathrm{n}^{\circ}$ 91.542, de 19/8/85), abolindo a contrapartida dos estados. Entre 1993 e 1994, foram definidos critérios para avaliação dos livros didáticos, com a publicação do documento "Definição de Critérios para Avaliação dos Livros Didáticos” (MEC/FAE/UNESCO).

O PNLD constitui-se numa "estratégia de apoio à política educacional implementada pelo Estado brasileiro com a perspectiva de suprir uma demanda que adquire caráter 
obrigatório" (HÖFLING, 2000, p. 159-160), determinada a partir da Constituição Federal de 1988 (CF/1988). Para reforçar sua argumentação, a autora apoia-se na CF/1988 que destaca "o dever do Estado com a educação será efetivado mediante a garantia de (...) VII - atendimento ao educando no ensino fundamental, através de programas suplementares de material didático-escolar, transporte, alimentação e assistência à saúde". Segundo Höfling (2000, p. 160), a "distribuição gratuita de livro didático tradicionalmente vem sendo entendida como uma das funções do Estado no que se refere ao fornecimento do material didático-pedagógico".

A preocupação com a qualidade dos livros se acentuou no início dos anos 1990, materializando-se na oportunidade de os professores de $1^{\mathrm{a}}$ a $4^{\mathrm{a}}$ série escolherem os livros. Dessa forma, em 1993, foi criada a primeira comissão de avaliação que estabeleceu, como critério de eliminação, os livros que contivessem preconceitos de qualquer natureza e erros conceituais na área disciplinar.

A avaliação pedagógica dos livros inscritos para o PNLD se inicia em 1996, lançando as bases para o atual programa do PNLD e suas posteriores ampliações. Após o processo de avaliação dos livros, o MEC elabora o Guia de Livros Didáticos, composto pelas resenhas das coleções consideradas aprovadas pela comissão.

A acuidade do MEC, com relação aos livros didáticos, expressa a preocupação com a qualidade, pois estabeleceu um conjunto de critérios tanto de natureza conceitual específico à área da obra, como também estipulou condicionalidades de âmbito mais geral, tais como não "veicular preconceitos de condição social, regional, étnico-racial, de gênero, de orientação sexual ou de linguagem, assim como qualquer outra forma de discriminação ou de violação de direitos", "fazer doutrinação religiosa ou política, desrespeitando o caráter laico e autônomo do ensino público" e "utilizar o material escolar como veículo de publicidade ou de difusão de marcas, produtos ou serviços comerciais".

Evidenciando a seriedade desse processo de avaliação, Höfling afirma que

Desde 1996 essas comissões têm atuado mais sistematicamente avaliando livros didáticos, e a época da divulgação de seus resultados é possível ler com muita frequencia matérias com títulos como "Editoras vão à Justiça contra o MEC" (Folha de S. Paulo, 21/5/96), "Autores de livros didáticos exigem lista 
do MEC" (Folha de S. Paulo, 13/1/97), em jornais de grande circulação. Até mesmo pressões diretamente exercidas sobre os pareceristas são relatadas pelos componentes das comissões de avaliação (HÖFLING, 2000, p. 168).

Em 1997, com a extinção da Fundação de Assistência ao Estudante (FAE), a responsabilidade pela política de execução do PNLD foi transferida, integralmente, para o FNDE, programa que foi ampliado até atingir todas as séries e componentes curriculares.

A partir de 2000, foi inserida no PNLD a distribuição de dicionários da Língua Portuguesa aos alunos dos anos iniciais do ensino fundamental, mas, em 2005, em vez de entregar uma obra para cada aluno, o FNDE passou a fornecer acervos de dicionários a todas as escolas públicas do ensino fundamental. $\mathrm{O}$ ensino médio passa a ser atendido integralmente pelo PNLD em 2011, inclusive na modalidade Educação de Jovens e Adultos.

Cabe destacar que, em 2012, o PNLD apresenta avanços tecnológicos com a publicação de edital para formação de parcerias para estruturação e operação de serviço público e gratuito de disponibilização de materiais digitais a usuários da educação nacional.

Além disso, também em 2012, pela primeira vez, as editores puderam inscrever no âmbito do PNLD 2014, objetos educacionais digitais complementares aos livros impressos. Esse novo material multimídia, que inclui jogos educativos, simuladores e infográficos animados, será enviado para as escolas em DVD para utilização pelos alunos dos anos finais do ensino fundamental no ano letivo de 2014. O DVD é um recurso adicional para as escolas que ainda não têm internet. Os novos livros didáticos trarão também endereços on-line para que os estudantes tenham acesso ao material multimídia, complemente o assunto estudado, além de tornar as aulas mais modernas e interessantes (BRASIL, 2012).

Na perspectiva de Munakata (2012, p. 59), há uma "relação simbiótica" entre o livro didático e a escola. O autor destaca, ainda, que "a expansão da escolarização amplia o público leitor de livros, e a existência destes - em particular, os destinados 
especialmente à escola - possibilita a própria escolarização da sociedade". Para Silva (2012, p. 817),

O Estado Brasileiro está intimamente ligado aos livros didáticos durante praticamente todo o Período Republicano. Estas relações se estreitam ainda mais a partir de 1985 com a criação do PNLD que, por sua vez, foi assumido, mantido e aperfeiçoado por governos subseqüentes.

Se, na visão de Silva (2012, p. 817), o PNLD se consolidou enquanto uma política de Estado e, por sua vez, "tornou o livro didático um objeto acessível para praticamente todos os estudantes de escolas públicas brasileiras", de outro lado, entendemos que essa política precisa ser revista de modo que passe a considerar a possibilidade do livro se tornar um produto consumível.

Atualmente, o funcionamento do PNLD pode ser sistematizado em seis etapas ou fases. Inicialmente, há a inscrição das editoras para participar de edital aberto pelo $\mathrm{MEC}$, momento em que submetem seus livros para análise. O edital estabelece, em detalhes, as regras para a inscrição do livro didático, desde as especificações técnicas, como a gramatura do papel, até o conteúdo a ser apresentado nas coleções didáticas.

Numa segunda etapa, ocorre a triagem e a avaliação dos livros recebidos pelo MEC, que os encaminha para o Instituto de Pesquisas Tecnológicas da Universidade de São Paulo (IPT), para avaliação da qualidade técnica da publicação. Em seguida, os livros selecionados são encaminhados à Secretaria de Educação Básica (SEB/ MEC), órgão responsável pela avaliação pedagógica. Atendidas as etapas iniciais, a SEB/MEC convida universidades públicas para analisar os livros didáticos, considerando a especificidade de cada área do conhecimento.

A terceira fase do processo é a confecção do Guia do Livro Didático com as avaliações dos livros aprovados, publicadas pelo FNDE em seu sítio eletrônico e em material impresso. Esse material é enviado às escolas cadastradas no Censo Escolar para que professores e equipe pedagógica procedam à análise das resenhas das coleções para selecionar as que melhor atendem ao "projeto político-pedagógico da escola; ao aluno e professor; e à realidade sociocultural das instituições". Após esse processo, a escola deve indicar/apontar a escolha e fazer o pedido de duas obras para cada ano/disciplina. 
Apesar de historicamente aperfeiçoada, esta política pública não está isenta de críticas, sobretudo, em relação à chegada das obras selecionadas pelos professores às escolas. Isso pode ocorrer porque:

Concluída a negociação, o FNDE firma um contrato com cada editora, com quantitativos baseados em projeções do número de alunos nas escolas, calculadas a partir do censo escolar mais atualizado. Não havendo acordo entre as partes em relação ao preço, o regulamento permite que o FNDE, em respeito ao princípio da economicidade, contrate a aquisição de obras escolhidas em segunda opção. $\mathrm{Na}$ eventualidade de novo impasse, o Fundo pode negociar a aquisição da obra mais escolhida na região da escola (BRITTO, 2011, p. 8).

Britto (2011) destaca que o percentual de escolas que deixam de enviar suas opções ao FNDE é da ordem de $20 \%$. Pela nossa experiência na/com as redes públicas de ensino podemos afirmar que uma das principais razões desse elevado índice é exatamente esse desgaste/desencanto causado pelo fato recorrente de suas escolhas não serem contempladas.

A produção dos livros pelas editoras consiste na penúltima fase do processo. Após a compilação dos dados dos formulários impressos e dos pedidos feitos pela internet, o FNDE inicia o processo de negociação com as editoras. A aquisição é realizada por inexigibilidade de licitação, prevista na Lei 8.666/93, tendo em vista que as escolhas dos livros são efetivadas pelos professores. Concluída a negociação, o FNDE firma o contrato e informa os quantitativos e as localidades de entrega para as editoras, que dão início à produção dos livros, com supervisão dos técnicos do FNDE.

O programa é executado em ciclos trienais alternados e:

[...] a cada ano o MEC adquire e distribui livros para todos os alunos de um segmento, que pode ser: anos iniciais do ensino fundamental, anos finais do ensino fundamental ou ensino médio. À exceção dos livros consumíveis, os livros distribuídos deverão ser conservados e devolvidos para utilização por outros alunos nos anos subseqüentes (BRASIL, 2012).

Aúltima etapa constitui-se propriamente na distribuição dos livros, que é realizada pelas editoras diretamente com as escolas, por meio de um contrato entre o FNDE 
e a Empresa Brasileira de Correios e Telégrafos (ECT). Cabe esclarecer que essa etapa do PNLD também conta com o acompanhamento de técnicos do FNDE e das secretarias estaduais de educação.

Na perspectiva de Silva (2012, p. 806), o livro didático está "consagrado em nossa cultura escolar" e "tem assumido a primazia entre os recursos didáticos utilizados na grande maioria das salas de aula do Ensino Básico". Daí depreende-se porque, mesmo no ensino particular, o uso de materiais didáticos similares (apostilas) ao livro didático tem encontrado receptividade em meio às famílias e sistemas escolares.

Outro aspecto identificado pelo autor é que "a importância do livro didático para muitos professores vai além de sua função como ferramenta didática". Para essa argumentação, Silva recorre a Franco (1982) que identificou em seus estudos que muitos professores utilizam-se desse instrumento didático "como fonte de consulta pessoal". Silva $(2012$, p. 807) conclui, dessa forma, que "o livro acaba sendo também o grande responsável pela informação e formação dos professores".

Para além de constituir-se num instrumento de "(in)formação" para professores, o livro didático precisa ser pensado como um elemento que pode contribuir para aumentar o capital cultural dos alunos e, consequentemente, de suas famílias.

\section{PNLD no contexto da municipalização e do "apostilamento" do ensino fundamental em São Paulo}

As políticas/reformas educacionais formuladas/implementadas a partir de meados da última década do século recém-findado, tanto em âmbito nacional quanto estadual, impeliram fortemente os municípios paulistas a se responsabilizarem, cada vez mais, pelo Ensino Fundamental (EF).

No plano Federal, a implementação de um abrangente programa de descentralização das políticas públicas sociais desde os anos 1990, que passou a transferir para os níveis sub-nacionais de governo grande parte das suas funções de gestão/ financiamento como expressão clara da reordenação/limitação do raio de ação do Estado neste campo, teve no Fundo de Manutenção e Desenvolvimento do Ensino 
Fundamental e de Valorização do Magistério (FUNDEF) ${ }^{1}$ a sua materialização maior na área educacional (ARRETCHE, 2002; SOUZA; FARIA, 2003).

Embora o FUNDEF tenha tido um impacto importante para a quase universalização do EF, mesmo que para tal tenha gerado vários "efeitos colaterais", a literatura especializada revela que sua principal implicação foi a de induzir a um acelerado e generalizado processo de municipalização desta etapa escolar no país.

Em função da histórica preponderância da rede estadual paulista na cobertura pública do ensino fundamental, formato diverso do instituído na maioria das outras unidades da Federação onde a participação municipal era próxima, igual ou até mesmo superior a do Estado na oferta de tal nível de ensino, São Paulo passou a assistir "[...] a um dos mais radicais (senão o mais!) e abruptos processos de municipalização já vivenciados no Brasil” (OLIVEIRA, 2004, p. 10), fruto do efeito combinado do advento do FUNDEF e da política/ação municipalista do governo estadual paulista no mesmo período.

Em face do referido processo, as administrações públicas municipais do Estado de São Paulo criam/ampliam seus sistemas/redes de ensino com a incorporação, no todo ou em parte, do ensino fundamental, passando assim a ter atribuições e responsabilidades não experienciadas anteriormente.

Carentes de estruturas materiais, físicas, humanas, financeiras, administrativas e pedagógicas para implantar políticas educacionais e dar continuidade a elas, sem experiência/preparo para gerir sistemas/redes de ensino fundamental e sem contar com a devida assistência por parte do governo estadual para materializar a municipalização, os municípios paulistas passaram a buscar, cada vez mais, alternativas/apoio no setor privado (ARELARO, 2007; OLIVEIRA et al., 2006; ROSSI, 2009).

Na perspectiva de alguns pesquisadores (ARELARO, 2007; ADRIÃO; BORGHI, 2008; ADRIÃO et al., 2009; CAIN, 2009; ROSSI, 2009) que, há algum tempo vem se debruçando sobre a temática em questão, o contemporâneo processo de municipalização do ensino fundamental deflagrado no âmbito do Estado de São Paulo acabou impulsionando o estabelecimento de parcerias educacionais entre as prefeituras paulistas e a esfera privada.

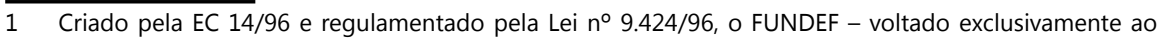
financiamento do EF - vigorou até o fim de 2006. 
Pesquisa $^{2}$ concluída pelo Grupo de Estudos e Pesquisas em Política Educacional (GREPPE) da UNESP/Rio Claro, abarcando o período de 1997 a 2006, identificou três modalidades principais de parcerias público-privada para a oferta da educação básica municipal no Estado de São Paulo: a compra de sistemas de ensino privados; a oferta de vagas em instituições de educação infantil privadas subvencionadas pelo poder público; e a assessoria para a gestão educacional. A referida pesquisa mostrou que essas parcerias se intensificaram a partir de 2005, sendo a aquisição dos chamados "sistemas apostilados de ensino" a mais freqüente.

Ao analisarem a tendência de crescimento das parcerias entre as prefeituras paulistas e as empresas educacionais (Anglo, COC, Objetivo, Positivo, entre outras) para a aquisição de sistemas apostilados de ensino, Adrião et al. (2009) revelam que 161 (25\%) dos 645 municípios de São Paulo já haviam "apostilado" suas redes de educação infantil e/ou ensino fundamental até o ano de 2007. Destes, $150(93,2 \%)$ eram municípios com até 50 mil habitantes ${ }^{3}$.

Segundo as autoras supracitadas $(2009$, p. 805$)$, trata-se, na grande maioria, de "municípios de pequeno porte que, na década de 1990, assumiram responsabilidades para com a oferta do nível obrigatório de ensino, para as quais, provavelmente não estavam preparados". Municípios com tal perfil tendem a ser mais permeáveis à pressão das empresas privadas educacionais, uma vez que possuem condições mais adversas, do ponto de vista político e operacional, para a oferta educacional.

Depreende-se, então, que a recente, crescente e polêmica tendência da aquisição de sistemas apostilados de ensino por municípios paulistas é fruto do despreparo técnico dos mesmos e da sua necessidade de responder às novas demandas educacionais assumidas a partir da segunda metade da década de 1990.

O interesse por parte das redes/empresas privadas de ensino, cujas matrículas encontram-se estagnadas desde os anos 1990, pelas redes municipais de ensino é tão grande que algumas delas chegaram a criar setores específicos para atender

2 Trata-se da pesquisa intitulada "Estratégias municipais para a oferta da educação básica: análise de parcerias público-privado no Estado de São Paulo", desenvolvida pelo GREPPE da UNESP/Rio Claro e coordenada pela Profa ${ }^{a} r^{a}$ Theresa Maria de Freitas Adrião.

3 Segundo recente pesquisa realizada pela Fundação Lemann, praticamente um terço dos municípios paulistas contam com sistemas apostilados privados em seus sistemas/rede de ensino. 
somente os municípios, visto atualmente como um novo e promissor mercado. O COC possui o Núcleo de Apoio à Municipalização do Ensino (NAME), o Objetivo mantém o Sistema Objetivo Municipal de Ensino (SOME) e o Positivo conta com o Sistema de Ensino Aprende Brasil.

Consolidada a parceria entre o poder público municipal e determinada empresa privada, esta passa a disponibilizar para o conjunto ou parte das escolas municipais os seus produtos/serviços educacionais, tais como: apostilas e cadernos de orientação para alunos e professores, $C D-R O M$ 's, treinamento para os professores, monitoramento do uso dos materiais adquiridos (ADRIÃO et al., 2009; ARELARO, 2007).

Não obstante, as conseqüências indesejáveis trazidas pelas parcerias firmadas entre o poder público local e as empresas particulares no âmbito educacional, já demonstradas por recente pesquisa, o "apostilamento" de escolas municipais de ensino fundamental vem sendo "bem visto" pelos pais/eleitores.

Além de uma percepção difusa que atribui superioridade ao setor privado em detrimento do setor público, outra razão encontrada para justificar a satisfação/ boa aceitação dos pais em relação à adoção dos sistemas apostilados de ensino pela administração pública municipal é a de que, diferentemente do que acontece com os livros didáticos, cada apostila recebida pelo aluno pode contribuir como capital cultural seu e de sua família, uma vez que não é devolvido para a escola ao término do ano letivo. Outro aspecto já assinalado neste texto é que a sua adoção pode colaborar com a prática didática do professor em sala de aula, já que o mesmo 'economiza' tempo ao não ter que passar conteúdos na lousa. Essa se constitui na nossa proposta de aperfeiçoamento do PNLD.

O depoimento de uma diretora da rede municipal de ensino de um pequeno município do interior paulista ilustra bem a posição favorável dos pais ao "apostilameto": "a maioria dos pais aprova o material, principalmente porque cada aluno tem o seu de graça e não é retornável” (CAIN, 2009, p. 124).

A aprovação da adoção do sistema apostilado de ensino em detrimento do livro didático fornecido gratuitamente aos municípios pelo PNLD também ocorre entre professores, que apontam, dentre outros, o benefício do aluno do sistema público de ensino poder deixar de copiar o conteúdo e as atividades constantes do livro 
didático - a ser devolvido ao final do período letivo - o que, em tempos de avançada tecnologia, inclusive no setor educacional, é pedagogicamente contraproducente.

Observando a tabela abaixo, percebemos que os municípios menores têm uma incidência consideravelmente maior na adoção destes materiais apostilados. Entre os municípios com menos de 50 mil habitantes, temos mais de $25 \%$ com estas parcerias, enquanto nos maiores, este percentual gira próximo aos $10 \% \mathrm{e}$ se considerarmos os oito maiores nenhum tem esta parceria com os "sistemas de ensino" privados.

Tabela 1 - Municípios paulistas que adotaram sistemas apostilados de ensino entre 1994 a 2007

\begin{tabular}{l|l|l|l}
\hline Município/porte & $\begin{array}{l}\text { Número total de } \\
\text { municípios: São } \\
\text { Paulo }\end{array}$ & $\begin{array}{l}\text { Total de municípios } \\
\text { que declararam ado- } \\
\text { tar algum "sistema } \\
\text { de ensino" }\end{array}$ & $\begin{array}{l}\text { \% de municípios } \\
\text { que adotam "sis- } \\
\text { tema de ensino" }\end{array}$ \\
\hline $\begin{array}{l}\text { Municípios muito } \\
\text { pequenos: até 10.000 } \\
\text { habitantes }\end{array}$ & 295 & 79 & $26,7 \%$ \\
\hline $\begin{array}{l}\text { Municípios pequenos: } \\
\text { de } 10.001 \text { a 50.000 mil } \\
\text { habitantes }\end{array}$ & 234 & 71 & $30,3 \%$ \\
\hline $\begin{array}{l}\text { Municípios médios: } \\
\text { de 50.001 a 100.000 } \\
\text { habitantes }\end{array}$ & 54 & 05 & $9,2 \%$ \\
\hline $\begin{array}{l}\text { Municípios grandes: } \\
\text { de 100.001 a 500.000 } \\
\text { habitantes }\end{array}$ & 54 & 06 & $11,1 \%$ \\
\hline $\begin{array}{l}\text { Municípios muito gran- } \\
\text { des: mais de 500.001 } \\
\text { habitantes }\end{array}$ & 8 & -- & -- \\
\hline \begin{tabular}{l} 
Total \\
\hline
\end{tabular}
\end{tabular}

Fonte: Adaptado de ADRIÃO et al. (2009).

Este processo tem uma série de implicações e efeitos negativos que incidem, de forma geral, sobre o sistema de ensino dos quais podemos destacar que essas aquisições são opção do Executivo e, na maioria das vezes, exclusivas do próprio prefeito. Poucos são os Conselhos Municipais de Educação que se posicionam sobre essa decisão, enquanto os Conselhos do FUNDEF e FUNDEB, quando muito, acompanham a prestação de contas e não opinam sobre a decisão já tomada pelo Executivo. Trata-se, portanto, de um retrocesso em relação à possibilidade 
de controle social sobre a implantação de políticas públicas previsto pela Constituição Federal de 1988.

Estes sistemas se caracterizam por uma fragilidade conceitual e pedagógica dos materiais e serviços comprados pelos municípios; além de existir na prática um duplo pagamento pelo mesmo serviço, uma vez que estes municípios em sua maioria participam do PNLD. Conforme Adrião et al. (2009, p. 809):

\begin{abstract}
Apesar de muitos depoimentos de dirigentes municipais de educação apontarem como principal motivação para a compra do sistema de ensino privado a baixa eficiência e problemas na distribuição dos livros destes programas federais, o fato é que, quando um município faz a opção por um sistema de ensino provado, há um duplo pagamento por materiais didáticos. A população já remunera empresas privadas do setor editorial, triadas por avaliação técnica para a produção de livros didáticos que integram os programas federais e cujo acervo está disponível gratuitamente às redes municipais de ensino. Os recursos que sustentam o PNLD são oriundos de orçamento do Ministério da Educação (MEC) destinado ao Fundo Nacional de Desenvolvimento da Educação (FNDE). A compra de materiais apostilados é efetuada com percentual dos recursos constitucionalmente vinculados à Manutenção e Desenvolvimento do Ensino, que poderiam ser destinadas a outros aspectos das atividades pedagógicas para melhoria da educação local.
\end{abstract}

Temos, ainda, a submissão do direito à qualidade do ensino à lógica do lucro e, por último, a padronização/homogeneização de conteúdos e currículos escolares como parâmetro de qualidade. Aspecto que trabalharemos no próximo tópico.

Entendemos, também, que um elemento desta necessária luta contra esta privatização e em defesa da educação pública é fazer com que o PNLD seja aprimorado no sentido que apontamos neste artigo.

\title{
40 PNLD como recurso didático
}

Partimos do pressuposto de que a maior aprovação por parte dos pais e de professores dos "sistemas apostilados" em detrimento do PNLD é motivada por diversos fatores, que vão além de uma percepção difusa da superioridade dos sistemas privados e se apoiam em questões objetivas do uso do material no cotidiano escolar. 
Essa percepção se apoia em resultados de pesquisa empírica (LIMA, 2013) realizada junto a uma rede de educação do interior do estado de São Paulo, num município com 13 mil habitantes, envolvendo todos os professores que lecionavam em 2011 no Ciclo I do Ensino Fundamental (CIEF), totalizando 36 docentes. A aplicação de questionário ocorreu em 2011 e abrangeu todos os professores do CIEF, sendo 15 da Escola Municipal 1 (EM1), 13 docentes da Escola Municipal 2 (EM2) e 8 da Escola Municipal 3 (EM3).

Considerando a temática deste artigo, indagamos os docentes pesquisados acerca do processo de elaboração do plano de ensino, sobre a escolha dos conteúdos a serem ensinados e como ocorreu o processo de escolha do PNLD durante o ano de 2010.

Os docentes pesquisados afirmaram que consideram na elaboração de seus planos de ensino respectivamente: o "aluno" (16), a "realidade do aluno, escola e município" (7) e os "PCNs" (7) dentre outros aspectos. Quanto à forma como elaboram seus planos de ensino, enfatizaram que as decisões são tomadas coletivamente em reuniões com todos os professores da rede municipal por série/ano (15), além de destacar o uso da pesquisa, estudo e o embasamento teórico (11), conforme Tabela 2. Percebe-se a valorização do trabalho coletivo e da reflexão, conforme descrição do sujeito 12 : "No período do planejamento, professores se reúnem por séries/ano e há uma grande reflexão sobre os objetivos e conteúdos e principalmente sobre a prática pedagógica".

\section{Tabela 2 - Elaboração do Plano de Ensino do CIEF}

\begin{tabular}{l|l|l}
\hline Categorias & Freq. & $\%$ \\
\hline $\begin{array}{l}\text { O aluno (interesse, relevância, dificuldades, aprendizagens, necessidades, } \\
\text { faixa etária, desenvolvimento) }\end{array}$ & 16 & 20 \\
\hline Reuniões coletivas com todos os professores da rede municipal por série/ano & 15 & 18,8 \\
\hline Pesquisando, estudando e tendo embasamento teórico & 11 & 13,8 \\
\hline Conhecimento da realidade do aluno, escola e município & 7 & 8,8 \\
\hline Parâmetros curriculares nacionais (PCN) & 7 & 8,8 \\
\hline Planos anteriores, modificando o que for necessário & 6 & 7,5 \\
\hline Período de planejamento & 5 & 6,3 \\
\hline Orientação e apoio da coordenação e direção & 4 & 5 \\
\hline Trocas de experiências com professores (anos anteriores) & 4 & 5 \\
\hline Resultado de avaliações externas & 3 & 3,8 \\
\hline Objetivos da escola e da Secretaria Municipal de educação & 2 & 2,5 \\
\hline Total de respostas & 80 & $100 \%$ \\
\hline
\end{tabular}

Fonte: LIMA (2013). 
Os professores da rede municipal pesquisada priorizaram o aluno como centro de todo o processo educativo, destacando que na elaboração dos seus planos consideram o interesse, as dificuldades, as aprendizagens, as necessidades, o estágio de desenvolvimento e a faixa etária das crianças. Dado que evidencia o uso do livro didático, visto que o mesmo possibilita aos docentes considerar sua realidade na elaboração de seu planejamento, sem desconsiderar outros aspectos também importantes, citados na Tabela 2. A ênfase no trabalho coletivo é algo muito significativo nesta rede municipal.

Com o intuito de comparar dados, questionamos também os professores sobre como ocorre a escolha dos conteúdos a serem ensinados no CIEF no cotidiano escolar.

\section{Tabela 3 - Escolha dos conteúdos ensinados aos alunos do CIEF}

\begin{tabular}{l|c|c}
\hline Categorias & Freq. & $\%$ \\
\hline $\begin{array}{l}\text { Os alunos (necessidades, interesse, realidade, estágio de desenvolvimen- } \\
\text { to, nível de interpretação) Sondagem inicial }\end{array}$ & 20 & 27,4 \\
\hline $\begin{array}{l}\text { Plano de ensino adequando as especificidades/desenvolvimento/anda- } \\
\text { mento da turma }\end{array}$ & 15 & 20,5 \\
\hline Estudos e análises das avaliações externas (mínimo de conteúdos) & 9 & 12,3 \\
\hline Parâmetros curriculares nacionais (PCN) & 7 & 9,6 \\
\hline $\begin{array}{l}\text { Conteúdos exigidos nacionalmente na matriz curricular/ Referências } \\
\text { curriculares/ Diretrizes nacionais }\end{array}$ & 5 & 6,8 \\
\hline Objetivos propostos & 4 & 5,5 \\
\hline Livros didáticos & 4 & 5,5 \\
\hline $\begin{array}{l}\text { Conteúdos significativos, desafiadores, que proporcionem avanço e } \\
\text { desenvolvimento integral do aluno }\end{array}$ & 3 & 4,1 \\
\hline O contexto social da escola e do aluno & 2 & 2,7 \\
\hline Conteúdos específicos da região são trabalhados em projetos & 1 & 1,4 \\
\hline Estudos e reflexão sobre a prática diária & 1 & 1,4 \\
\hline Pesquisando & 1 & 1,4 \\
\hline Enfatizo a leitura, escrita e cálculo & 73 & 1,4 \\
\hline Total de respostas & $100 \%$ \\
\hline
\end{tabular}

Fonte: LIMA (2013).

Denota-se, pela análise da Tabela 3, a prevalência do aluno como elemento chave na escolha do conteúdo dado na sala de aula do CIEF, considerando 
suas necessidades, interesses, realidade, estágio de desenvolvimento, nível de interpretação, suas especificidades e o andamento da turma, além do resultado das avaliações externas.

Os dados presentes nas Tabelas 2 e 3 sinalizam que os planos de ensino utilizados em anos anteriores são consultados visando a elaboração dos novos planos, embora não sejam mencionados na escolha dos conteúdos. Já os livros didáticos e as matrizes curriculares nacionais são apontadas apenas na escolha dos conteúdos, mas são desconsiderados nas respostas dos professores pesquisados na elaboração dos planos de ensino.

Outro dado interessante é a presença da categoria "orientação e apoio da coordenação e direção" para a elaboração dos planos de ensino e a sua ausência na escolha dos conteúdos. Pode-se supor que o primeiro momento é entendido pelos professores como mais burocrático, enquanto o segundo, a escolha dos conteúdos, refere-se ao seu trabalho diário em sala de aula, que pode ser denominado de plano de aula.

Verifica-se também uma ênfase no aluno, além da realidade local e dos documentos nacionais e estaduais mediante reuniões e reflexões para chegarem à elaboração de caminhos capazes de alcançar o objetivo da escola na formação de cidadãos que buscam a qualidade do ensino público. A rede municipal tem enfatizado uma preocupação com o coletivo, pois os planos de ensino são elaborados em reuniões com todos os professores municipais, envolvendo as três unidades escolares. Isso foi confirmado na análise de conteúdo dos planos de ensino, visto que eles eram idênticos. A rede municipal planeja momentos de discussão e elaboração coletiva dos planos de ensino entre os seus professores.

Os dados evidenciam a importância de desenvolver um planejamento que considera a realidade local da escola e dos seus alunos, o que é possível assegurar com o PNLD. No entanto,

A tentativa de padronização dos projetos pedagógicos e do trabalho realizado nas escolas é a principal justificativa dos dirigentes municipais de Educação para a realização de parcerias com os sistemas de ensino privados. Buscam instaurar nas redes municipais uniformidade nos processos pedagógicos, alegando evitar "desigualdades" entre as escolas. Se tal motivação revela uma preocupação com a possibilidade de que ações diferenciadas 
gerem qualidade também diferenciada, por outro lado, incide sobre a autonomia de escolas e docentes frente à organização do trabalho pedagógico ao retirar-lhes, como assegura a LDB, a possibilidade de organizarem suas práticas a aprtir de necessidades locais ou iniciativas próprias (ADRIÃO et. al., 2009, p. 810).

Indagamos os professores sobre como ocorreu a escolha do PNLD de 2010 na rede municipal (Tabela 4).

Tabela 4 - Escolha do PNLD/2010 do CIEF

\begin{tabular}{l|l|l}
\hline Categorias & Freq. & $\%$ \\
\hline $\begin{array}{l}\text { Coletivamente por série/ano, envolvendo toda a rede municipal, com } \\
\text { discussões e reuniões entre professores e coordenação. Inicialmente a } \\
\begin{array}{l}\text { análise em cada escola e posteriormente com toda a rede. Escolhemos o } \\
\text { mais adequado }\end{array}\end{array}$ & 15 & 39,5 \\
\hline Não participei, visto que não trabalhava na rede municipal & 11 & $29 \%$ \\
\hline Por professores da mesma série contemplando o planejamento & 5 & 13,1 \\
\hline Em reunião de professores e no HTPC & 2 & 5,3 \\
\hline Coletivo & 2 & 5,3 \\
\hline Não houve escolha & 1 & 2,6 \\
\hline Em branco & 1 & 2,6 \\
\hline A partir do manuseio de livros expostos (editoras) & 1 & 2,6 \\
\hline Total de respostas & 38 & 100 \\
\hline
\end{tabular}

Fonte: LIMA (2013).

A seleção dos livros didáticos referentes ao PNLD ocorreu de modo semelhante à elaboração do plano de ensino, conforme Tabela 4. Para 39,5\% dos professores, essa escolha se dá coletivamente por série/ano, envolvendo toda a rede municipal, com discussões e reuniões entre professores e coordenação. Inicialmente, a análise é realizada em cada escola e, posteriormente, é realizada uma reunião coletiva com toda a rede municipal para a decisão final do livro mais adequado. Alguns professores afirmaram não participarem dessa escolha, pois adentraram a rede municipal, recentemente, por meio de concurso público. Abaixo, alguns depoimentos dos professores pesquisados.

Primeiramente os livros recebidos para análise foram analisados na própria escola, pelos professores. Posteriormente, os profes- 
sores de toda rede municipal (séries iniciais) se reuniram para socializarem as análises e fazer as escolhas (Sujeito 1).

Os professores escolheram os livros que melhor contemplaram com o planejamento (Sujeito 13).

A escolha foi coletiva, através de vários encontros para discussões até chegar a uma escolha (Sujeito 17).

Coletivamente, primeiramente entre os professores e coordenadores de cada escola e depois, num segundo momento, entre os professores e coordenadores de todas as escolas, analisando e discutindo cada um, por série (Sujeito 18).

Por meio do PNLD, a escola e os professores podem escolher, dentre as coleções aprovadas, os livros didáticos que melhor atendam ao projeto político pedagógico da escola, ao contexto social e cultural dos alunos. Entendemos que essa escolha proporciona aos profissionais da educação um momento rico de reflexão e discussão coletiva, conforme dados empíricos apresentados anteriormente.

O uso do livro didático consumível significa um instrumento metodológico relevante no processo de construção de conhecimento dos alunos da educação básica, contribuindo para uma aprendizagem significativa, visto que possibilita ao professor o desenvolvimento de diversas atividades com os alunos em sala de aula utilizando o livro didático de fato, como recurso didático para: escrever, recortar, colar, manipular, ler, entre outras. Evitando o que ocorre atualmente, que é o excesso de cópias da lousa ou do próprio livro didático, visto que o mesmo deverá ser usado nos anos subseqüentes. Dessa forma, defendemos que, ao término de cada ano letivo, o livro didático possa ser dado aos alunos para futuros estudos, pesquisas, além de auxiliá-los em atividades educativas na continuidade de estudos.

A flexibilidade de organizar o planejamento pedagógico da sala de aula com o uso do livro didático é muito mais adequado que a "obrigatoriedade" e o "engessamento" de apostilas que, no nosso entendimento, tolhem a autonomia profissional do professor.

No desenvolvimento deste estudo, constamos a fragilidade da estrutura de muitos municípios, principalmente os de pequeno porte, em relação a equipe pedagógica da secretaria municipal de educação, o que geralmente é um aspecto significativo que os direcionam a adquirir os sistemas apostilados de instituições privadas, conforme aponta em outra pesquisa Adrião et al. (2009, p.811) . 
A precariedade técnico-operacional encontrada nos municípios frente às suas responsabilidades para com a oferta de educação básica parece estar no cerne dessa busca de qualidade por meio da padronização. Os dirigentes municipais entrevistados reconhecem limites de natureza técnico-pedagógica para se instituir um ensino de qualidade, tais como ausência de um quadro técnico qualificado para oferecer suporte ao trabalho desenvolvido nas unidades escolares, ou ainda precariedades na formação docente para as quais a alternativa seria o oferecimento de materiais apostilados, além de assessoria promovida pela instituição privada produtora do material. Transfere-se, assim, ao setor privado a gestão do processo pedagógico de toda a rede de ensino, aderindo-se a um "padrão de qualidade" estabelecido no âmbito do mercado. (ADRIÃO, et al. 2009, p. 811).

Sugerimos ao Estado e à União que, utilizando proposta semelhante a dos sistemas apostilados, proporcionem às secretarias municipais de educação uma assessoria pedagógica, que elaborem proposta de apoio pedagógico aos municípios, no sentido técnico, essencialmente nas questões pedagógicas e curriculares, permitindo aos professores participar do processo de debate e escolha dos livros a serem utilizados pela escola.

\section{O livro didático como capital cultural do aluno}

Com a massificação do ensino no período do pós-guerra europeu, a visão sobre a capacidade dos sistemas escolares em promover igualdade e justiça começou a sofrer os primeiros abalos, sobretudo, porque as expectativas mais otimistas sobre o papel da escola na sociedade não se confirmaram.

Para Nogueira e Nogueira (2002), Bourdieu teve o mérito de formular, a partir dos anos 1960, uma resposta original, abrangente e bem fundamentada, teórica e empiricamente, para o problema das desigualdades escolares. Essa resposta tornou-se um marco na história, não apenas da Sociologia da Educação, mas do pensamento e da prática educacional em todo o mundo. Sua teoria estava ancorada na perspectiva de forte relação entre o desempenho escolar e a origem social dos educandos.

Existe consenso sobre a abrangência e importância da obra de Bourdieu para a compreensão dos processos de desempenho escolar, pois foi graças a ela que se abandonaram definitivamente as explicações sobre sucesso/fracasso escolar 
baseado apenas no mérito pessoal ou em capacidades inatas ao indivíduo. Dessa forma, demonstra-se que a escola reproduz as desigualdades já existentes na sociedade e que questões como renda, cultura e posição social se mostravam determinantes para o sucesso escolar dos jovens.

De fato, quando a análise é feita no plano macrossocial das relações entre as classes, Bourdieu tem boas razões para ser pessimista. Essa análise, no entanto, não pode ser transposta diretamente para o plano microssociológico. Existem diferenças significativas no modo como cada escola e/ou professor participa desse processo de reprodução social. Essas diferenças foram, em grande medida, negligenciadas por Bourdieu (NOGUEIRA; NOGUEIRA, 2002).

A escola, ao tratar a todos de forma igual, em direitos e deveres, acaba por privilegiar os grupos que por sua bagagem familiar já são privilegiados. A aprendizagem exige que os receptores dominem os códigos utilizados na produção dessa comunicação, uma vez que a escola se utiliza de padrões da cultura dominante. Assim, grupos familiarizados com esta cultura têm, naturalmente, mais facilidade em sua vida escolar, o que é constantemente interpretado ou como capacidade inata ou de inteligência própria do indivíduo. Na contramão desse pensamento, Bourdieu sinaliza que as diferenças de acesso à cultura geral e, como decorrência, as consequentes diferenças de aquisição da cultura escolar são determinantes para o sucesso e/ou fracasso escolar.

Nessa perspectiva, o capital cultural pode existir sob três formas: no estado incorporado, ou seja, sob a forma de disposições duráveis do organismo; no estado objetivado, sob a forma de bens culturais (quadros, livros, dicionários, instrumentos, máquinas), e por fim, o estado institucionalizado, em que o certificado escolar garante o reconhecimento social e institucional do capital cultural (BOURDIEU, 1998).

Cabe destacar que, na perspectiva de Bourdieu, o capital cultural constitui (na sua forma incorporada) o elemento da bagagem familiar que teria o maior impacto na definição do destino escolar. A sociologia da educação de Bourdieu se notabiliza, justamente, pela diminuição que promove no peso do fator econômico, comparativamente ao cultural, na explicação das desigualdades escolares. Inicialmente, a posse de capital cultural favoreceria o desempenho escolar na medida em que facilitaria a aprendizagem dos conteúdos e códigos escolares (NOGUEIRA; NOGUEIRA, 2002). 
O capital econômico e o social funcionariam apenas como meios auxiliares na acumulação do capital cultural. No caso do capital econômico, permitindo o acesso a determinados estabelecimentos de ensino e a bens culturais mais caros, como viagens de estudo. Contudo, o benefício escolar extraído dessas oportunidades depende sempre do capital cultural previamente possuído (NOGUEIRA; NOGUEIRA, 2002).

Setton (2005), em pesquisa sobre alunos de classes populares que atingiram cursos elitizados da USP, demonstrou a importância que estes indivíduos atribuíram ao acesso à leitura, embora essa leitura não seja a dos materiais pedagógicos e não esteja restrita aos livros indicados pelos professores.

Reforçando o argumento em defesa do livro didático, Tagliani, apoiada em autores como Rojo e Batista (2003, p. 44), destaca que

[...] é importante que se considere o papel do LD como 'instrumento que favoreça a aprendizagem do aluno, no sentido do domínio do conhecimento e no sentido da reflexão na direção do uso dos conhecimentos escolares para ampliar sua compreensão da realidade [...]' (TAGLIANI, 2011, p. 139).

Para Tagliani (2011, p. 137), o livro didático "[...] representa, em muitos casos, a única possibilidade de leitura tanto no ambiente escolar quanto no ambiente familiar do aluno". Esse contexto aponta para os benefícios do aluno ficar com o livro didático, uma vez que o acesso a livros está diretamente ligado ao poder econômico.

Mesmo considerando que o capital cultural depende, em grande medida, de múltiplos fatores como o próprio contexto cultural familar, consideremos que para o aluno das classes sociais menos favorecidas ter a posse dos livros didáticos utilizados em sua formação seria um benefício relevante para além de tempo e espaços escolares.

\section{Os custos do PNLD}

Considerando a pertinência e mesmo as vantagens que decorreriam da mudança na forma de distribuição dos livros didáticos, elaboramos uma projeção/análise dos custos do PNLD em seu formato atual e também com a alteração da proposta. Com base no orçamento de 2011 e em previsões para 2012 e 2013, considerando os custos atuais despendidos com o PNLD, em relação ao orçamento do MEC, 
chegamos ao valor gasto com o PNLD, que varia entre 0,7 bilhões previstos para 2012 e 1 bilhão gasto em 2011, uma média de 1,3\% do orçamento total do MEC, de 63,7 bilhões anuais.

Desta forma, fizemos uma projeção dos gastos com o PNLD para o período de um triênio (2011-13), considerando que é este o tempo de reposição dos livros de acordo com a organização atual do sistema. Tem-se, neste período, um gasto previsto de 2,4 bilhões com o PNLD, incluindo desde o processo de avaliação até a aquisição e distribuição dos livros, o que representa um percentual aproximado de $1,3 \%$ do orçamento do MEC no período.

Em nossa proposta de distribuição de livros consumíveis, atingiríamos um gasto de 5 bilhões no mesmo período, totalizando um percentual de $2,7 \%$ do orçamento do Ministério da Educação.

Analisando esses dados, podemos concluir que o custo efetivo da mudança traria benefícios já apontados por um custo relativamente baixo, de aproximadamente $1,4 \%$ do orçamento anual do MEC. Apesar de triplicar o número de livros distribuídos, teríamos o custo do programa dobrado, considerando que os gastos com algumas fases do processo, como análise, divulgação e escolha dos professores continuariam inalterados. Possibilitarse-ia, assim, que os livros fossem entregues diretamente aos alunos, em vez de serem propriedade da escola.

Para localizar as "questões reais" mencionadas acima, remetemo-nos a estudo realizado pela Fundação Lemann (2009), que constata que há 200 municípios conveniados por Sistemas de Ensino no Estado de São Paulo, o que mostra a rápida expansão: dos 154, em 2006, para 200, em 2009. Neste estudo foram analisados diversos aspectos, tais como o livro do aluno, o livro do professor, a capacitação e acompanhamento pedagógico e a avaliação dos usuários sobre os diferentes serviços e produtos oferecidos pelos sistemas de ensino.

Para além de identificar os provedores de produtos e serviços que caracterizam sistemas de ensino e identificar os municípios que o adotaram, a pesquisa pretendeu analisar a adoção dos produtos/serviços em cinco cidades do Estado de São Paulo. Para tanto, foram selecionados aqueles com mais de 35 mil habitantes e que utilizassem convênios há mais de quatro anos contínuos. 
Depois, foram selecionadas quatro escolas municipais, e entrevistados profissionais da educação (secretários de educação, diretores, coordenadores pedagógicos e professores de $1^{\mathrm{a}}$ a $4^{\mathrm{a}}$ séries), totalizando 70 entrevistas em 20 estabelecimentos.

Como resultado, o estudo da Fundação Lemann (2009) concluiu que o uso do livro (apostila) pelo aluno teve aprovação de mais de $90 \%$ dos professores, destacando que o uso do material estimula o aprendizado, pois os alunos "copiam menos; leem, refletem e estudam mais".

Para o professor, o uso do livro/apostila ajuda a potencializar o seu trabalho no espaço familiar mediante o uso de tarefas escolares, já o aluno passa a consultar e a ler o livro também no espaço privado, e não apenas na escola quando, atualmente, em virtude do livro didático não ser consumível, o professor precisa solicitar a leitura e cópia de trechos do livro. O livro é um recurso didático muito interessante, visto que além do conteúdo curricular, também apresenta recursos que chamam a atenção dos alunos, como imagens, charges, tabelas, gráficos, fotografias, obras de arte, letras de músicas, além de uma variedade de atividades elaboradas pedagogicamente para desenvolver uma aprendizagem significativa nos alunos.

Outro elemento positivo constatado com o uso das apostilas foi com relação à mudança nas práticas do professor e na própria rotina das aulas, pois ao usar menos a lousa, o professor consegue dispor de mais tempo para explicar o conteúdo e acompanhar de perto os alunos que apresentam dificuldades na aprendizagem.

De acordo com o estudo, a percepção sobre satisfação dos pais é elevada, representando $93 \%$ de satisfação com o sistema de ensino apostilado, em contrapartida, apenas $7 \%$ não estão satisfeitos ou não sabe opinar.

Entendemos que os benefícios elencados pelo uso do sistema apostilado, apresentados ao longo deste artigo, e os citados pela pesquisa da Fundação Lemann (2009), poderiam ser facilmente obtidos com a disponibilização dos livros do PNLD para os alunos conforme nossa proposta de aperfeiçoamento do programa. Importante ressaltar que esta disponibilização, comparativamente aos gastos com os sistemas apostilados de ensino, se mostra significativamente mais econômica. Isto fica comprovado quando consideramos os dados trazidos por Britto (2011, p. 14): 
Para fins de comparação com os programas federais de material didático, é preciso ter em mente que este custo diz respeito ao material de todas as disciplinas. De fato, os custos unitários no âmbito do PNLD, são de aproximadamente R \$ 6,50. Mas este valor deve ser multiplicado pelo número de livros utilizados, para que se possa estimar o custo do programa por aluno. No caso do ensino médio, por exemplo, para cada aluno são destinados sete livros reutilizáveis e quatro livros consumíveis, o que significaria um custo estimado de 41 reais por aluno ano.

Lembremo-nos de que os dados também trazidos por Britto (2011) apontam que o custo médio do sistema apostilado é de R $\$ 150,00$ por aluno/ano. Assim, mesmo se, de acordo com nossa proposta, todos os livros fossem consumíveis, o custo com os livros didáticos (que ficariam em $\mathrm{R} \$ 71,50$ por aluno/ano, no caso do ensino médio) seria menos da metade do sistema apostilado. Ressalta-se, ainda, o fato de o livro didático passar por processo altamente qualificado academicamente de avaliação quanto aos seus conteúdos e metodologia, o que não ocorre com os sistemas apostilados.

Outro ponto que cabe ressaltar é a aproximação da proposta de tornar o livro didático consumível como o programa "Literatura em minha casa", no qual a pesquisa de Rigoleto (2009, p.152) constatou que algumas escolas não distribuíram e outras não trabalharam os livros de Literatura. Mas, com os alunos das professoras que trabalharam, percebeu-se que "todas as crianças entrevistadas leram os livros do kit, umas leram os cinco títulos, outras leram de dois a três livros. Algumas crianças relataram ter emprestado os livros a primos e colegas que não eram de suas classes".

Tanto para as crianças quanto para as mães, a experiência de compartilhar a leitura era nova. Muitas dessas famílias nunca tinham experimentado ler um livro juntos. Por isso, apontaram aspectos positivos desta experiência como a união, bastante citada pelas crianças; o fato de aprender e de poder tirar dúvidas com as mães; o sentimento de que os pais estão participando da educação, isto tanto por parte dos filhos, quanto dos pais; a diversão de poder cantar e rir com a mãe, como no caso de $T$; e, talvez, o mais importante: a construção de uma relação de confiança, de cumplicidade e de intimidade entre mães e filhos (RIGOLETO, 2009).

Cabe destacar que, embora os livros de literatura sejam muito diferentes dos livros didáticos, o impacto significativo da presença de livros nas casas onde, antes, não havia nenhum - ou só a Bíblia - é bastante significativo. 
Por fim, outra questão de relevância é que os livros, tanto didáticos quanto os demais, continuarão a ser importantes durante muito tempo, embora, talvez em longo prazo, venham a ser substituídos pela leitura em aparelhos eletrônicos.

\section{Considerações finais}

O artigo teve como objetivo problematizar uma importante dimensão da educação na atualidade e propor sugestões para o aperfeiçoamento do PNLD, considerando sua importância para a qualidade da educação brasileira. Para tanto, recuperamos inicialmente a trajetória de constituição dos programas de distribuição de livros didáticos, discutindo as principais alterações sofridas ao longo da história brasileira, situando o livro didático como elemento importante na formação do capital cultural do próprio aluno e de forma estendida à sua família, além de um excelente recurso didático.

Diante do exposto, entendemos que, se a apostila que é adquirida pelas administrações municipais fica permanentemente com o aluno e isso é bem visto/avaliado pelos pais e profissionais da educação por proporcionar ganhos pedagógicos, os livros didáticos do PNLD - até como uma estratégia para tentar frear a surpreendente tendência de apostilamento/invasão privada nas escolas públicas municipais paulistas - também poderiam deixar de ser retornáveis, sem prejuízos de todo o processo já consolidado do PNLD e com ganhos para os alunos.

O término da política de reutilização do livro didático no Brasil certamente demandaria um investimento maior por parte do governo federal na educação. Mas, não tão impactante, conforme demonstrado no texto, devido dentre outros aspectos, ao fato desta esfera de poder já ser a maior financiadora e compradora de livros didáticos do país e à própria economia de escala do PNLD, o qual possui um considerável histórico de alterações e aperfeiçoamentos. E tudo indica, como se procurou demonstrar neste artigo, que este seria um investimento de alto retorno em termos de qualidade da Educação e de sua democratização. 


\section{Referências}

ADRIÃO, T. BORGHI, R. Parcerias entre as prefeituras e a esfera privada: estratégias privatizantes para a oferta da educação básica? In: ADRIÃO, T.; PERONI, V. (Org.). Público e privado na educação: novos elementos para o debate. São Paulo: Xamã, 2008, p. 99-110.

ADRIÃO, et al. Uma modalidade peculiar de privatização da educação pública: a aquisição de "sistemas de ensino" por municípios paulistas. Educação \& Sociedade, Campinas, v. 30, n.108, p. 799-818, out. 2009.

ARELARO, L. R. G. Formulação e implementação das políticas públicas em educação e as parcerias público-privadas: impasse democrático ou mistificação política. Educação \& Sociedade, Campinas, v. 28, n.100 - Especial, p. 899-919, out. 2007.

ARRETCHE, M. Relações federativas nas políticas sociais. Educação e Sociedade, Campinas, v. 23, n. 80, p. 25-48. 2002.

BOURDIEU, P.; PASSERON, J. C. Escritos de educação. Petrópolis: Vozes, 1998.

BRASIL. Programa Nacional do Livro Didático (PNLD). 2012. Disponível em: $<$ http://portal.mec.gov.br/index.php?Itemid=668\&id=12391\&option=c om_content\&view=article $>$. Acesso em: 23 jan. 2012.

BRITTO, T. F. O Livro Didático, o Mercado Editorial. Brasília, DF: Centro de Estudos da Consultoria do Senado, 2011.

CAIN, A. A. O atendimento ao ensino fundamental: análise de parcerias de dois municípios paulistas e o setor privado na aquisição de sistemas de ensino. Rio Claro, 2009. 271f. Dissertação (Mestrado em Educação)-Instituto de Biociências de Rio Claro, UNESP.

HÖFLING, E. de M. Notas para discussão quanto à implementação de programas de governo: em foco o Programa Nacional do Livro Didático. Educação \& Sociedade, ano 21, n. 70, abr., 2000, p. 159-170. 
LIMA, V. M. M. Formação de Professores e Currículo dos Anos Iniciais do Ensino Fundamental do Município de Tupi Paulista. Relatório de Pesquisa. Faculdade de Ciências e Tecnologia; FCT; UNESP. 2013.

MUNAKATA, K. O livro didático como mercadoria. Pro-Posições, São Paulo, v. 23, n. 3(69), p. 51-66, set./dez. 2012.

NOGUEIRA, M. A.; NOGUEIRA, C. M. M. A sociologia da educação de Pierre Bourdieu: limites e contribuições. Educação \& Sociedade, Campinas, ano 23, n. 78 , abr., 2002.

OLIVEIRA, C. et al. Conselhos Municipais de Educação: um estudo na região metropolitana de Campinas. Campinas, SP: Alínea, 2006.

OLIVEIRA, R. P. FUNDEF: uma análise preliminar. Educação: Teoria e Prática, v. 12, n. 22, p. 5-11, jan./jun. 2004.

RIGOLETO, A. P. C. Programa Literatura em minha casa enquanto Política Pública: avaliando a formação de famílias leitoras. Dissertação (Mestrado em Educação)-Universidade Estadual Paulista, UNESP, Presidente Prudente, 2009.

ROSSI, L. Oferta educacional e parceria com o setor privado: um perfil dos municipios com até 10.000 habitantes. Rio Claro, 2009. 181f. Dissertação (Mestrado em Educação)- Instituto de Biociências de Rio Claro, UNESP, 2009.

SETTON, M. da G. J. Um novo capital cultural: predisposições e disposições à cultura informal nos segmentos com baixa escolaridade. Revista Educação e Sociedade, Campinas, v. 26, n. 90, p.77-105, jan./abr. 2005.

SILVA, M. A. A fetichização do livro didático no Brasil. Educação e Realidade, Porto Alegre, v. 37, n. 3, p. 803-821. set./dez. 2012.

SOUZA, D. B. de S,; FARIA, L. C. M. de. (Org.). Desafios da educação municipal. Rio de Janeiro: DP\&A, 2003.

TAGLIANI, D. C. O livro didático como instrumento mediador no processo de ensino aprendizagem de língua portuguesa: a produção de textos. RBLA, Belo Horizonte, v. 11, n. 1, p. 135-148, 2011. 


\section{A proposal for improving the PNLD as public policy: the textbook as the cultural capital of the student/family Abstract}

The article discusses an important dimension of education today and points out suggestions for the improvement of the National Textbook Program (PNLD), considering its importance to the improvement of the quality of Brazilian education. The methodological procedures adopted for the preparation of this work are made up of bibliographic and documentary research, a questionnaire with 36 teachers of the early years of elementary education in a municipal education network in the State of São Paulo. We argue that PNLD can constitute an element for increasing the cultural capital of students, especially the weaker sections of society, who, in general, do not have access to books, and that it can be a relevant teaching resource in the pedagogical work of teachers. We propose, through critical analysis, that the PNLD distributes, to every basic education student, textbooks that really belong to them. Keywords: Textbook. PNLD. Public Policy. Cultural Capital.

\section{Una propuesta para mejorar el PNLD como política pública: el libro de texto como capital cultural del estudiante/familia Resumen}

El artículo se propone discutir la necesidad de reformular el Programa Nacional de Libros de Texto (PNLD) en Brasil, considerándolo un elemento que contribuye para la expansión del capital cultural de los estudiantes, especialmente de los más desfavorecidos y, por ende, mejorar la calidad de la educación brasileña. Los procedimientos metodológicos adoptados en la elaboración de este trabajo se componen de investigación bibliográfica y documental, un cuestionario aplicado a 36 docentes del primer ciclo de la educación primaria en una red municipal de educación en el Estado de San Pablo. Argumentamos que el PNLD puede aumentar el capital cultural de los estudiantes, especialmente de los sectores más desamparados de la sociedad, que, en general, no tienen acceso a los libros, y también puede ser importante como recurso didáctico en el trabajo pedagógico de los docentes. Además de recuperar la discusión de la adopción del libro de texto, este trabajo aboga por cambios en el PNLD, proponiendo que todos los estudiantes de la educación Básica comiencen a recibir sus libros.

Palabras clave: Libro de Texto. PNLD. Políticas Públicas. Capital Cultural. 